Paidéia, 2005, 15(30), 141-145

\title{
VISITA DOMICILIAR AO PORTADOR DE TRANSTORNO DE HUMOR: RELATO DE EXPERIÊNCIA ${ }^{1}$
}

\author{
Mariluci Camargo Ferreira da Silva Candido ${ }^{2}$ \\ Luiz Jorge Pedrão \\ EERP - Universidade de São Paulo
}

\begin{abstract}
Resumo: O profissional de saúde depara-se com o portador de transtorno de humor em diversos tipos de atendimento e a depressão maior é um de seus tipos mais comuns. Neste estudo, procurou-se relatar a experiência de uma doutoranda do programa de Pós-graduação em Enfermagem Psiquiátrica da Escola de Enfermagem de Ribeirão Preto - Universidade de São Paulo numa situação de visita domiciliar a um portador do referido transtorno em fase de depressão maior. Espera-se que o relato desta experiência sensibilize e divulgue conhecimentos sobre a depressão maior, contribuindo para a superação do estigma, da falta de informação e da prática ineficaz.
\end{abstract}

Palavras-chave: depressão maior; visita domiciliar de enfermagem; transtorno de humor.

\section{VISIT DOMICILIAR PAYABLE TO THE BEARER OF UPSET OF HUMOR: REPORT OF EXPERIENCE}

\begin{abstract}
The health professional is confronted with patients who suffer from mood disturbances in various kinds of assistance, and major depression is one of the most common types. This study aimed to report on the experience of a doctoral student of the Post-graduation program in Psychiatric Nursing of the College of Nursing in Ribeirão Preto - University of São Paulo, in a situation of home visits to a patient of the aforesaid disturbance in the major depression phase. It is hoped that the report of this experience calls attention and divulges knowledge about major depression, contributing to the overcoming of the stigma, the lack of information and inefficient practice.
\end{abstract}

Key-words: major depression; nursing home visit; mood disturbance.

\section{Introdução}

A depressão, caracterizada principalmente por tristeza, perda de interesse em atividades de interesse e diminuição da energia, é o transtorno mental mais comum e é considerado um grave problema de saúde pública. Estima-se que, atualmente, 121 milhões de pessoas sofram deste transtorno, sendo 5,8\% homens e 9,5\% mulheres, que vivenciam algum episódio depressivo durante a sua vida (World Health Organization, 2001).

\footnotetext{
${ }^{1}$ Artigo recebido para publicação em 28/06/2004; aceito em 05/01/ 2005

${ }^{2}$ Endereço para correspondência: Luiz Jorge Pedrão, Departamento de Enfermagem Psiquiátrica e Ciências Humanas, Escola de Enfermagem de Ribeirão Preto/USP, Av. Bandeirantes 3900, CEP: 14040-902, Ribeirão Preto/SP, E-mail: lujope@eerp.usp.br
}

O portador de transtorno mental sempre esteve presente na sociedade, permeando o cuidado de enfermagem, independente da área de atuação profissional, pois o ser humano desde a sua existência é acometido por este transtorno, e, nesse sentido, declara que a dor psíquica é concomitante com a condição humana (Silva, 2001; Taylor, 1992).

Cerca de $31 \%$ a $50 \%$ da população brasileira apresenta durante a vida pelo menos um episódio de algum transtorno mental, e 20\% a 40\% necessita, em decorrência desses transtornos, de algum tipo de ajuda profissional (Dalgalarrondo, 2000).

Ressalta-se que muitos profissionais têm resistência em trabalhar com os portadores de transtornos mentais. Isso sugere reflexões acerca da possível relação entre as ações em saúde mental do enfermeiro (inclusive no cuidado ao indivíduo com de- 


\section{Mariluci Camargo Ferreira da Silva Candido}

pressão maior) com: a sua formação profissional (graduação), a falta de conhecimento adequado do enfermeiro para o cuidado em saúde mental, a submissão profissional e também as dificuldades em lidar com suas próprias emoções, como os demais profissionais (Silva, 2001).

Assim, propõe-se, neste relato, apresentar a experiência de uma doutoranda em visita domiciliar a um portador de depressão maior, realizada durante a atividade prática de disciplina de Pós-graduação.

\section{Contextualizando O Cenário}

A disciplina "Assistência nos transtornos psiquiátricos” oferecida pelo Programa de Pós-graduação em Enfermagem Psiquiátrica da Escola de Enfermagem de Ribeirão Preto - Universidade de São Paulo (EERP/USP) - Departamento de Enfermagem Psiquiátrica e Ciências Humanas (EPCH), requer como atividade prática: a realização de aproximação a um portador de transtorno mental escolhido pela pós-graduanda, para observação e avaliação de enfermagem quanto ao seu estado mental. Tem-se como objetivo com esta atividade aproximar o pós-graduando do portador de transtorno mental, observar e discutir as condições clínicas, socioeconômicas, culturais, ambientais e afetivas do indivíduo no contexto familiar.

A partir da proposta de atividade prática surgiu a idéia de descrever a experiência da pósgraduanda no processo da visita a um portador de depressão maior em seu domicílio. A portadora de transtorno de humor com depressão maior foi escolhida para entrevista por ser o tema da área de pesquisa e de interesse da pós-graduanda.

A localização da residência do portador de transtorno do humor e o contato ficaram a cargo da pós-graduanda. O conhecimento da existência dessa pessoa se deu através de contato anterior na unidade básica de saúde, feito na época em que a pósgraduanda trabalhava na comunidade de um município do interior do Estado de São Paulo. A atenção ocorreu em virtude do portador apresentar uma história clínica de recaída: reaparecimento ou recrudescimento do quadro clínico de uma doença, estando o paciente em convalescença e recorrências: reaparecimento de sintomas da doença após a remissão deles (Dorland, 1997).
Esse momento traduziu-se, ao mesmo tempo, na coleta de dados para uma discussão importante da disciplina, e também numa oportunidade de ajudar essa pessoa, oferecendo informações sobre a depressão maior, com a intenção de contribuir para a prevenção de recaídas e recorrências, manutenção da saúde física e mental e no tratamento deste transtorno.

\section{Desenvolvimento Da Visita Domiciliar}

Foi feito contato prévio através de uma primeira visita domiciliar para apresentação da pesquisadora, da atividade e consulta a cliente a respeito da sua participação na atividade referida. Foram dadas orientações verbais de que se tratava de uma atividade prática da disciplina de pós-graduação e ela foi consultada sobre a decisão de participar ou não. A partir da concordância da cliente para a segunda visita domiciliar, procedeu-se o agendamento do dia e horário do próximo encontro. Vale lembrar que o vínculo estabelecido entre indivíduo-profissional favorece o processo de comunicação verbal e não verbal (Stefanelli, 1993).

Desse modo, a relação cliente-profissional estabelecida anteriormente (a pós-graduanda foi enfermeira da unidade básica de saúde nesta comunidade) facilitou o desenvolvimento do processo de comunicação.

Sabe-se também da importância de um ambiente adequado para o desenvolvimento de qualquer processo de comunicação. Um ambiente tranqüilo, ou seja, livre de sons, de pessoas interferindo e confortável, proporciona a sensação de se sentir mais à vontade para comunicar-se.

O local onde se dá o processo de comunicação enfermeiro-cliente deve ser selecionado pelo enfermeiro, podendo atuar como fator determinante de certos tipos de resposta. Quando o cliente é visitado ou entrevistado em seu quarto, num recanto ou em sua casa, a comunicação tende a ser mais eficaz. O ambiente pode afetar o comportamento das pessoas e elas tendem a sentir segurança em um local conhecido e insegurança em face do desconhecido (Potter \& Perry, 1999; Stefanelli, 1993).

Escolheu-se dia e horário em que o portador estivesse disponível e coincidentemente a entrevista deu-se num horário em que havia privacidade total. Somente no final da visita é que o esposo da cliente chegou e foi convidado a participar. 
Planejou-se a utilização das técnicas de comunicação terapêutica e informações sobre a depressão maior durante a visita domiciliar. A orientação se deu por um roteiro de avaliação do cliente psiquiátrico, sugerido na disciplina da pós-graduação referida, tomando o cuidado para que esse momento de interação não ficasse voltado somente à seqüência do roteiro, mas que permitisse a comunicação livre e espontânea dos envolvidos, para que essa comunicação pudesse ser terapêutica.

Os profissionais de saúde lidam o tempo todo com pessoas, sejam esses clientes, família ou colegas de equipe. Por inúmeras vezes, o papel de entrevistador é exercido concomitantemente com o de terapeuta. Por isso, faz-se necessário a tomada de consciência de suas falhas na comunicação. As barreiras pessoais como o uso de termos técnicos, palavras que sugerem preconceitos, impaciência, mensagem incompleta, expressão inadequada de sentimentos e emoções, formação profissional ou cultural e status de uma pessoa em uma determinada organização são apontados como as mais comuns (Silva, 1996).

Nesse estágio de vida profissional, não se trata de uma primeira experiência em visita domiciliar e contato com um portador de depressão maior, mas da confirmação mais uma vez, que cada momento de comunicação é sempre único, pois cada um destes geram emoções e resultados imprevisíveis.

Ressalta-se que mesmo que se tenha um processo de comunicação com as mesmas pessoas, executando o mesmo procedimento, este momento é único e não se dá do mesmo modo em outras situações semelhantes (Stefanelli, 1993).

No dia 19 de abril de 2003, às $17 \mathrm{~h}$ e $30 \mathrm{~m}$ a enfermeira foi ao domicílio do participante, conforme (data e horário) combinado. A senhora $\mathrm{N}$. a recebeu e a convidou para que entrasse. Sentaram-se à mesa da cozinha. Novamente, foram feitos os devidos esclarecimentos quanto à atividade da pesquisadora, já dadas antes da entrevista, orientada por um roteiro semi-estruturado, sem a obrigatoriedade de segui-lo a risca.

De posse do roteiro sugerido pela disciplina da pós-graduação, passou-se à entrevista. A senhora N. referiu ter 44 anos, ser casada, secretária de escola, católica, mãe de três filhos e com ensino médio completo.
Quando indagada sobre o possível fator desencadeante da depressão maior perguntou: "qual é a causa da depressão?”. Passou-se como orientação que em se tratando de depressão, não se fala em causa, mas sim em fatores predisponentes, porque não existia uma causa isolada e sim fatores combinados que desencadeavam o aparecimento dos transtornos de humor; que era um transtorno multifatorial, ou seja, que o conjunto ou a soma dos fatores podem favorecer o aparecimento da depressão, como: situações vitais estressantes (perda de emprego ou de um ente querido), casos de depressão na família, ser mulher, conflitos psicológicos mal resolvidos na infância. Foi explicado que cada indivíduo reage de um modo a esses fatores, que cada um tem uma história. Também foi esclarecido que o termo depressão é conhecido recentemente como transtorno de humor.

Após a explicação acima, disse que a mãe e a irmã mais nova tiveram episódios de depressão nos últimos dois anos; referiu ter vivenciado algumas situações de estresse.

A ocorrência de vários casos na família vem confirmar a agregação familiar das alterações de humor e ser mulher como fator de risco para o desenvolvimento da depressão (Andrews, Szabo \& Burns, 2002; Kaplan, Sadock \& Benjamin, 1997; Lafer \& Vallada, 1999; Lindeman, Hamalainen, Isometã, Kaprio, Poikolainen \& Keikkinen, 2000; Stuart \& Laraia, 2001).

Continuando o relato, em março de 1987, por ocasião do nascimento do primeiro filho e da permanência do recém-nascido por 15 dias no hospital, ficou muito "nervosa" e ansiosa e chorava com facilidade. E, ao mesmo tempo, a mãe, que lhe fazia companhia, precisou ausentar-se. Neste período, a cliente não recebeu nenhum diagnóstico ou tratamento profissional referente aos sinais e sintomas que apresentava.

Acredita-se que a cliente pode ter tido um episódio de depressão menos severa. Sabe-se que qualquer doença física ou mental quando detectada e tratada precocemente tem mais probabilidade de um prognóstico favorável. É essencial que qualquer tipo de profissional seja capaz de reconhecer, encaminhar ou tratar a depressão, bem como prevenir recaídas.

No ano de 1989, a cliente teve a segunda gravidez com a presença de pré-eclâmpsia. Após o parto, refere ter tido muito sono, rigidez maxilar, choro 


\section{Mariluci Camargo Ferreira da Silva Candido}

fácil, sentir-se ansiosa e não conseguir pegar o recém-nascido. A exemplo da primeira gravidez, também não recebeu diagnóstico ou cuidados profissionais no que se refere às características emocionais apresentadas.

Ao que parece, nesta época, os profissionais de saúde que cuidaram da gestante e da puérpera não perceberam as manifestações de sintomas e sinais emocionais.

A cliente relata a terceira gravidez no ano de 1991 quando apresentou polihidrâmnio, perda de peso, rigidez muscular generalizada, diminuição da concentração e da coordenação corporal, falta de energia, choro fácil (sem motivo aparente) e passou por várias internações para hidratação venosa. Referiu que esse quadro recebeu do médico o diagnóstico de miastenia, o que gerou muita ansiedade e angústia; com o tempo esse diagnóstico foi desconsiderado. Mais uma vez, não foi considerado nenhum transtorno emocional para essa cliente.

A cliente, como já foi referido, é católica e através de orientação do pároco local é que foi alertada sobre a hipótese da presença de depressão. Este ofereceu folhetos informativos, conversou sobre a doença e sugeriu a ajuda de um especialista.

Os religiosos são vistos como colaboradores no trabalho com as doenças mentais, exercendo esclarecimentos e encaminhamentos para os profissionais de saúde (OPAS, 1999).

Aproximadamente, entre 1991 e 1992, surgiram as características clínicas: irritabilidade, choro fácil, diminuição da concentração, "moleza”, sonolência, gastrite; sentimentos de culpa, inutilidade e desesperança, perda de apetite, dificuldade para higiene pessoal e isolamento social. A cliente tinha retornado ao seu trabalho de secretária de escola, depois de um afastamento por dois anos, mas não conseguiu assumir sua função profissional, pois não conseguia escrever, era como se "faltasse força para escrever". O tempo de duração desse momento foi de duas semanas ou mais. Nesta época, recebeu o diagnóstico médico de depressão; fez terapia analítica por mais ou menos dois meses, mas não continuou por motivos financeiros (alto custo).

Quando interrogada sobre recorrência ou recaída da depressão, referiu já ter tido "mais ou menos” cinco vezes e que por várias vezes iniciara o tratamento farmacológico. No entanto, quando ocorria a remissão dos sintomas, interrompia o uso de medicamentos. A última recaída deu-se em janeiro de 2003 e disse perceber que os episódios acontecem quando há uma "sobrecarga emocional”: o período junho de 2002 foi marcado por uma reprovação em concurso público; em dezembro de 2002, passou por um aumento de responsabilidade no trabalho, tendo de tomar decisões em função do afastamento do chefe, e no lar, com a viajem do esposo a trabalho.

Ao final da entrevista, chegou o esposo da cliente que foi convidado a participar da mesma. Ele aceitou e informou que "quando não tinha informação sobre depressão, não entendia, achava que ela não se esforçava para melhorar, que era falta de força de vontade”. O casal ressalta que até hoje, qualquer material novo, o pároco lhes envia.

Atualmente, $\mathrm{N}$. não tem queixas clínicas, mas tem a compreensão de que o tratamento tem um tempo mínimo e dependendo das manifestações clínicas precisa ser contínuo, sem interrupção. Faz tratamento medicamentoso, passa por consulta médica a cada dois meses e faz sessões semanais de Reiki.

Ela foi orientada pela pesquisadora quanto à importância da inclusão da atividade física diária (caminhada), da manutenção regular do sono (dormir um número de horas suficiente para o seu padrão de sono ou pelo menos oito horas) e da adoção de alimentação equilibrada, para ajudar a prevenir novos episódios de depressão.

\section{Considerações Finais}

Esta experiência reafirmou que os profissionais de saúde, ainda nos dias de hoje, necessitam voltar a sua atenção ao ser humano, e para as suas características físicas e mentais, assim como para a alteração das mesmas.

O enfermeiro e a equipe de enfermagem constituem-se em profissionais de saúde que permanecem a maior parte do tempo com os portadores de transtornos de humor nos diferentes serviços de saúde. Daí a importância de desenvolver e aprimorar o cuidado de enfermagem para que seja mais eficaz.

O enfermeiro deve ser sensibilizado quanto às atividades essenciais a serem desenvolvidas ao portador de transtorno de humor, a sua família e a comunidade, tais como: a investigação e identificação de 
casos; encaminhamentos necessários, informações pertinentes ao transtorno de humor como fatores predisponentes, tratamento, quadro clínico, prevenção de recaídas e recorrências, entre outros.

A depressão maior é um sério problema de saúde pública, fazendo com que os portadores necessitem de ajuda profissional.

Espera-se que este estudo sensibilize e divulgue conhecimentos sobre a depressão maior a partir do reconhecimento das características clínicas da mesma, contribuindo para a superação do estigma, da falta de informação e da prática ineficaz ao portador de depressão.

\section{Referências Bibliográficas}

Andrews G., Szabo M. \& Burns J. ( 2002). Preventing major depression in Byoung people. The British Journal of Psychiatry, 181, 460-462.

Dalgalarrondo, P. (2000). Psicopatologia e Semiologia dos Transtornos Mentais. Porto Alegre: Artes Médicas.

Dorland. Dicionário Médico (1997). 25. ed. São Paulo: Roca.

Kaplan, H. I., Sadock B. \& Benjamin J. (1997). Compêndio de Psiquiatria: Ciências do comportamento e psiquiatria clínica, Porto Alegre: Artes Médicas.

Lafer, B. \& Vallada, H. (1999). Genética e fisiopatologia dos transtornos depressivos. Revista Brasileira de Psiquiatria, 21, (1), 12-17.

Lindeman, S., Hamalainen, J., Isometã, E., Kaprio, J. Poikolainen, K. \& Heikkinen, M. (2000). The 12month prevalence and risk factors for major depressive episode in Finland: representative sample of 5993 adults. Acta Psychiatrica Scandinavica, 102, 178-184.

Organização Panamericana de Saúde (OPAS). (1999). Modulo para la capacitacion de la enfermera general en la identificación y manejo de los transtonos afectivos. Programa de Salud Mental-División de Promoción de la Salud.
Potter, P.A. \& Perry, A. G. (1999). Fundamentos de Enfermagem: conceitos, processo e prática. Rio de Janeiro: Guanabara Koogan.

Silva, M. C. F. da (2001). Depressão: Pontos de vista e conhecimento do enfermeiro da rede básica de saúde. Dissertação de Mestrado. Escola de Enfermagem - USP, Ribeirão Preto.

Silva, M. J. P. da (1996). Comunicação tem remédio: A comunicação nas relações interpessoais em saúde. São Paulo: Robe Editorial.

Stefanelli, M. C. (1993). Comunicação com paciente: teoria e ensino. São Paulo: Robe Editorial.

Stuart, G. W. \& Laraia, M. T. (2001). Enfermagem Psiquiátrica: princípios e prática. Porto Alegre: Artmed Editora.

Taylor, C. M. (1992). Fundamentos de enfermagem psiquiátrica de Mereness. Porto Alegre: Artes Médicas.

World Health Organization. Mental and neurological disorders. Fact sheet. No 265. December 2001. Disponível em: http://www.who.int/ mediacentre/factsheets/fs265/en/print.html. [2004 